\title{
Interaction of Fear Conditioning with Eyeblink Conditioning Supports the Sensory Gating Hypothesis of the Amygdala in Men
}

\author{
Lana Inoue, ${ }^{1}$ Thomas Michael Ernst, ${ }^{1}$ - Inda Inat Ferber, ${ }^{1,2}$ CChristian Josef Merz, ${ }^{3}$ Dagmar Timmann, ${ }^{1}$ \\ and Giorgi Batsikadze ${ }^{1}$
}

https://doi.org/10.1523/ENEURO.0128-20.2020

${ }^{1}$ Department of Neurology, Essen University Hospital, University of Duisburg-Essen, 45147 Essen, Germany, ${ }^{2}$ Department of Biotechnology, Tel Hai College, Tel Hai 1220800, Israel, and ${ }^{3}$ Faculty of Psychology, Institute of Cognitive Neuroscience, Department of Cognitive Psychology, Ruhr University Bochum, 44780 Bochum, Germany

\begin{abstract}
Inhibition of the amygdala slows down acquisition of conditioned eyeblink responses (CRs). Based on the two-stage or two-factor theory of aversive conditioning, amygdala-dependent conditioned fear is a necessary prerequisite to acquire eyeblink CRs but is no longer needed after eyeblink CRs are attained. According to the sensory gating hypothesis of the amygdala, on the other hand, the amygdala modulates the salience of unconditioned stimuli (USs) and conditioned stimuli (CSs) in eyeblink conditioning. We tested these two opposing assumptions in five groups of 20 young and healthy men. On day 1, three groups underwent fear acquisition training followed by acquisition of eyeblink CRs. On the next day (day 2), extinction was tested. In group 1, fear and eyeblink extinction trials overlapped; in group 2, fear and eyeblink extinction trials alternated; and in group 3, fear extinction trials were followed by eyeblink extinction trials. Groups 4 and 5 were control conditions testing fear and eyeblink conditioning only. Preceding fear acquisition training facilitated acquisition of conditioned eyeblinks. Concomitant fear extinction impeded extinction of eyeblink CRs, which was accompanied by increased autonomic responses. Fear extinction, however, was not significantly altered by concomitant eyeblink extinction. Recall of fear CRs on day 2 was facilitated in group 1, suggesting additive response summation. Findings are difficult to explain with the two-stage theory of aversive conditioning, which predicts the suppression of conditioned fear once conditioned eyeblinks are acquired. Facilitated acquisition and impeded extinction of eyeblink CRs, however, are in accordance with the sensory-gating hypothesis of the amygdala.
\end{abstract}

Key words: amygdala; cerebellum; eyeblink conditioning; fear conditioning; fear extinction

\section{Significance Statement}

It has been proposed that conditioned eyeblink responses, once established, may help to facilitate fear extinction. This has potential clinical relevance because the extinction of learned fear responses is at the core of exposure therapy in the treatment of many anxiety disorders. Based on our findings, this proposal has to be rejected. Our findings do not support the two-stage theory of aversive conditioning, which predicts the suppression of conditioned fear once conditioned eyeblinks are acquired. Rather, we found that concomitant extinction of conditioned eyeblink and fear responses facilitated the recall of conditioned fear responses and impeded the extinction of conditioned eyeblinks. Findings are best explained by increased salience of conditioned stimuli and, therefore, support the sensory-gating hypothesis of the amygdala.

Received April 1, 2020; accepted August 4, 2020; First published September 3, 2020.

The authors declare no competing financial interests.
Authors contributions: L.I., T.M.E., C.J.M., D.T., and G.B. designed research; L.I. and G.B. performed research; L.I., T.M.E., I.I.F., and G.B. analyzed data; L.I., C.J.M., D.T., and G.B. wrote the paper. 


\section{Introduction}

Eyeblink conditioning is one of the most widely used paradigms to understand the underlying neural mechanisms of associative motor learning (for review, see Gerwig et al., 2007; Bracha et al., 2009; De Zeeuw and Ten Brinke, 2015). The contribution of the cerebellum has been studied in great detail (McCormick and Thompson, 1984). Fear conditioning, on the other hand, has been extensively used to study emotional learning, which relies centrally on the role of the amygdala (LeDoux, 2000; Phelps and LeDoux, 2005). Although studied in much less detail, the amygdala is also known to be involved in eyeblink conditioning. For example, inhibition of the amygdala slows down acquisition of conditioned eyeblink responses (Weisz et al., 1992; Neufeld and Mintz, 2001; Lee and Kim, 2004; Farley et al., 2016, 2018), whereas prior fear acquisition training facilitates the acquisition of conditioned eyeblinks (Neufeld and Mintz, 2001). The two-stage or two-factor theory of aversive conditioning is most commonly used to explain these observations (Konorski, 1967; Rescorla and Solomon, 1967; Thompson et al., 1987; Lennartz and Weinberger, 1992; Mintz and Wang-Ninio, 2001). In the first and fast stage, unspecific aversive responses, that is, conditioned fear responses, are thought to be acquired as an expression of learning and memory within the amygdala. In the second and slower stage, the specific aversive response, that is, the conditioned eyeblink response, is learned, which depends on associative plasticity within the cerebellum. Based on this two-stage theory of aversive conditioning, learned fear is a necessary prerequisite to acquire conditioned eyeblink responses, but is no longer needed after acquisition of the latter has occurred. In fact, a third stage of learning has been proposed, in which the initially acquired fear responses are extinguished. Magal and Mintz (2014) found that electrical activation of the cerebellar nuclei [mimicking conditioned response (CR) output] suppressed activation of the amygdala to an aversive periorbital electrical stimulation [mimicking the unconditioned stimulus (US)] in rats. The authors suggested that once conditioned eyeblinks are learned, the CR-related output of the cerebellar nuclei inhibits the US-related signal in the amygdala, leading to extinction of the amygdala-dependent conditioned fear responses. A comparable inhibitory feedback loop between the cerebellar nuclei and the inferior olive is known to contribute to the extinction of conditioned eyeblink responses in unpaired trials

This work was supported by a grant from the German Research Foundation (DFG; project \#316803389-SFB 1280) to D.T. (Subproject A05) and C.J.M. (Subproject A09), and a scholarship from the Essener Ausbildungsprogramm "Labor und Wissenschaft" für den ärztlichen Nachwuchs (ELAN) to L.I. I.I.F.'s stay at University Hospital Essen was funded with a scholarship of the Ministry of Culture and Science of the German State of North-Rhine Westphalia for students from Israel.

Correspondence should be addressed to Giorgi Batsikadze at giorgi. batsikadze@uk-essen.de.

https://doi.org/10.1523/ENEURO.0128-20.2020

Copyright @ 2020 Inoue et al.

This is an open-access article distributed under the terms of the Creative Commons Attribution 4.0 International license, which permits unrestricted use, distribution and reproduction in any medium provided that the original work is properly attributed.
(Hesslow and Ivarsson, 1996; Medina et al., 2002; Bengtsson et al., 2007).

Recently, the two-stage (or three-stage) theory of learning has been challenged. Farley et al. (2016) found that inactivation of the amygdala impaired not only acquisition but also retention of conditioned eyeblink responses. Furthermore, amygdala-dependent modulation did not require memory consolidation in the amygdala (Steinmetz et al., 2017). Both observations are at variance with the two-stage theory. The authors proposed an alternative hypothesis, known as the sensory-gating hypothesis of the amygdala, with the amygdala gating inputs about the conditioned stimulus (CS) to the cerebellum. Gating of the CS is conceptualized as increasing selective attention to the CS, leading to increased salience of the CS and therefore increased cerebellar learning (Farley et al., 2016). The amygdala has known monosynaptic projections to the pontine nuclei (Mihailoff et al., 1989; Farley et al., 2016), and there is experimental evidence that the amygdala modulates eyeblink conditioning through these projections (Farley et al., 2018). More recent findings show that connections of the amygdala to the locus ceruleus and periaqueductal gray also play a role (Farley and Freeman, 2019).

Differentiation between these two assumptions has potential clinical relevance: in case the two-stage (or threestage) theory is correct, eyeblink conditioning should, once the initial fast learning phase has been achieved, eventually suppress the amygdala. Conditioned eyeblinks, but possibly also other forms of cerebellar-dependent motor learning, may modify pathologic fear responses (Magal and Mintz, 2014). Although any clinical application would require that effects are longer lasting, and it is unclear whether the suppression is equally present in the presence of a US eliciting fear, this suppression may help to facilitate fear extinction, which is at the core of exposure therapy in the treatment of many anxiety disorders (for review, see Craske and Mystkowski, 2006; Craske et al., 2014). In case the sensory-gating hypothesis of the amygdala is correct, the amygdala continues to play a modulatory role in eyeblink conditioning once conditioned responses have been acquired. Therefore, conditioned eyeblinks should not alter or even impede the extinction of conditioned fear responses. We tested these two opposing possibilities in young and healthy human participants. On the first day, conditioned fear responses were acquired before the acquisition of conditioned eyeblink responses. On the second day, concomitant extinction of conditioned fear and conditioned eyeblink responses was performed.

\section{Materials and Methods}

\section{Participants}

Because menstrual cycle and oral contraceptives influence the acquisition and extinction of conditioned fear (Merz et al., 2018), only male participants were included in this study. The required sample size for the present study was calculated with G*Power software (Faul et al., 2009). One hundred participants divided into five groups were 
Day 1. Acquisition training
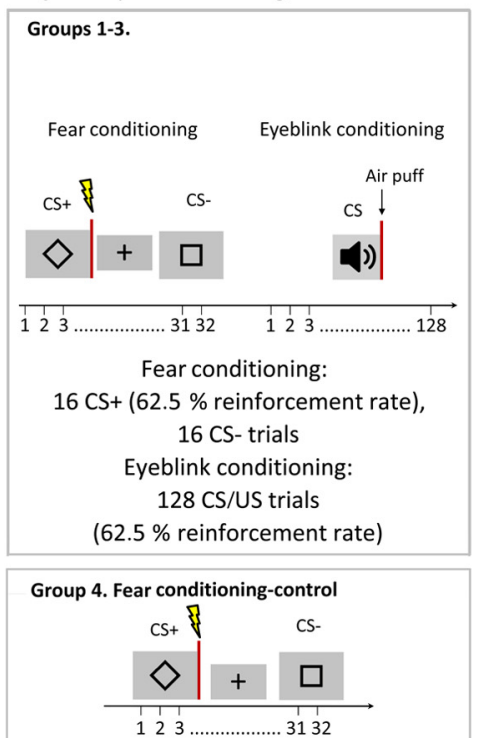

$16 \mathrm{CS}+(62.5 \%$ reinforcement rate), 16 CS- trials

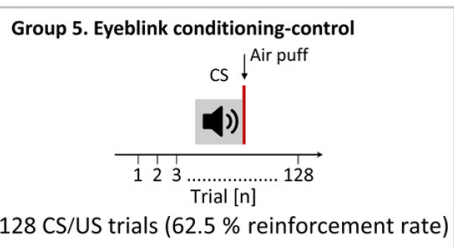

Day 2. Extinction training

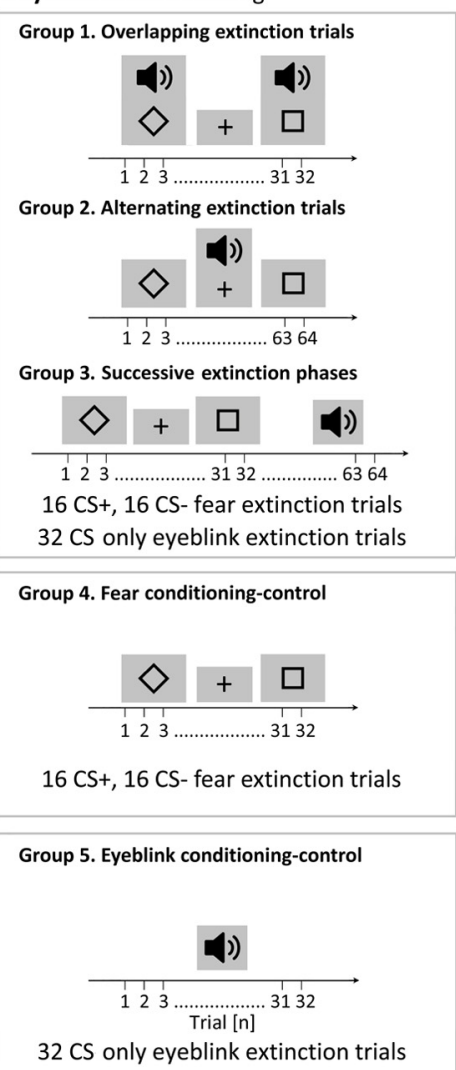

Figure 1. Summary of the experimental protocols in groups 1-5. Acquisition training protocols on day 1 are shown in the left column, and extinction training protocols on day 2 are shown in the right column. In fear conditioning, two geometrical figures (diamond and square) served as CSs, and electric shock (indicated by the flash symbol and red line) served as USs. In eyeblink conditioning, a tone (indicated by the speaker symbol) served as CS, an air puff as US (indicated by arrow and the red line). The number of trials is given on the $x$-axis. Between fear-conditioning trials, a fixation cross was shown. Further details can be found in the text.

required to obtain a medium $(f=0.25)$ effect size (Cohen, 1988), with a given significance level of $\alpha=0.05$, an assumed correlation among repeated measurements of $r=0.35$, and a power $(1-\beta)$ of 0.9 .

One hundred ten young and healthy male participants were recruited. Six participants had to be excluded from the analysis for technical reasons. Four participants did not finish the experiment. One hundred participants were included in the analysis (mean age, $23.58 \pm 3.26$ years; age range, 18-32 years). All participants were right handed according to the Edinburgh Handedness Inventory (Oldfield, 1971) with the group median [interquartile range (IQR)] score of $100(82.95-100)$ on a point scale of -100 (pure left hander) to 100 (pure right hander). Only participants without any neurologic or psychiatric disorder were included. None were taking centrally acting drugs, and none were smoking more than 10 cigarettes per month. All participants had normal or corrected-to-normal vision and did not wear contact lenses regularly (which may impact eyeblink conditioning).

Each participant underwent neurologic examination before the start of the experiment, which was always unremarkable. Participants' depression, anxiety, and stress levels were assessed using the DASS-21 (Depression, Anxiety and Stress Scale - 21 Items) questionnaire (Henry and Crawford, 2005; Norton, 2007). Scores were within the following normal ranges: depression score, median 2 (IQR, 0-4); anxiety score, 2 (IQR, 0-4.5), stress score, 6 (IQR, 2-10). Participants were asked to refrain from alcohol consumption $1 \mathrm{~d}$ before the experiment, and from caffeine $2 \mathrm{~h}$ before the experiment. The study was approved by the Ethics Committee of the University Hospital Essen and conforms to the principles laid down in the Declaration of Helsinki. All participants signed the written informed consent form. Participants were compensated for their participation with $60 €$.

\section{Methods}

Participants sat in a comfortable chair in front of a computer screen. The paradigms were implemented using the software Presentation (version 16.4; Neurobehavioral Systems). Participants were randomly assigned to one of five groups (20 participants/group; Fig. 1). The experiment was performed on 2 consecutive days. In Groups 1-3, fear acquisition training was performed followed by eyeblink acquisition on day 1. Partial reinforcement rates were used to slow down extinction learning (for review, see Lonsdorf et al., 2017). On day 2, extinction training 
took place. In group 1 ("overlapping extinction trials"), fear and eyeblink extinction trials were presented simultaneously. In group 2 ("alternating extinction trials"), individual fear and eyeblink extinction trials alternated. Based on the findings by Magal and Mintz (2014), the proposed modulatory effects on the amygdala were expected to be most prominent during the presentation of the eyeblink CS. Thus, effects on the extinction of learned fear responses were expected to be more prominent in group 1 ("overlapping extinction trials") compared with group 2 ("alternating extinction trials"). Groups 3, 4, and 5 were control groups. In group 3 ("successive extinction phases"), fear extinction training was followed by eyeblink extinction. In group 4 ("fear conditioning-control"), fear acquisition training was performed on day 1 , and fear extinction training on day 2. In group 5 ("eyeblink conditioning-control"), eyeblink acquisition training was performed on day 1 , and eyeblink extinction on day 2 .

Physiologic data [i.e., skin conductance responses (SCRs) and eyeblink electromyography (EMG)] responses, were recorded at a $1 \mathrm{kHz}$ sampling rate with a modular measurement station with corresponding amplifier modules and propriety recording software (MP160, EDA100C, EMG100C, AcqKnowledge 5.0.2, BIOPAC Systems). Verbal reports of subjective experiences were used as additional outcome parameters (for review, see Lonsdorf et al., 2017).

\section{Fear conditioning}

Differential fear conditioning was performed with two geometrical figures of identical brightness (diamond and square) serving as conditioned stimuli $\left(\mathrm{CS}^{+}, \mathrm{CS}^{-}\right.$; Fig. 1; Merz et al., 2014; Utz et al., 2015). Geometrical figures were shown in black color against a gray background with a duration of $8 \mathrm{~s}$. Between visual stimulus presentations, a black fixation cross on gray background was displayed [intertrial interval (ITI), $12 \pm 1.2 \mathrm{~s}$ ].

During fear acquisition training, $16 \mathrm{CS}^{+}(62.5 \%$ reinforcement rate) and $16 \mathrm{CS}^{-}$trials were presented in a pseudorandomized order. During fear extinction training, a total of $32\left(16 \mathrm{CS}^{+}\right.$and $\left.16 \mathrm{CS}^{-}\right)$fear CS-only trials were presented. In group 1 (overlapping extinction trials), eyeblink CS-only onset was jittered and started $2144 \pm 722 \mathrm{~ms}$ (range, between 943 and $3347 \mathrm{~ms}$ ) after fear CS-only onset (ITI, $12 \pm 1.2 \mathrm{~s}$ ). In group 2 (alternating extinction trials), eyeblink CS-only trials alternated with fear CS-only trials (ITI, $15.1 \pm 3.2 \mathrm{~s}$ ). In group 3 (successive extinction phases), fear and eyeblink extinction training were performed as separate blocks, with the fear extinction training preceding eyeblink extinction training (interval between phases, $25 \mathrm{~s}$; ITI between fear extinction trials, $18 \pm 1.2 \mathrm{~s}$; ITI between eyeblink extinction trials: $12 \pm 1.2 \mathrm{~s}$ ). A total of 32 eyeblink CS-only trials were presented in groups 1-3. In group 4 (fear extinction-control), only fear CS-only trials were presented (ITI, $18 \pm 1.2 \mathrm{~s})$.

A total of $16 \mathrm{CS}^{+}$and $16 \mathrm{CS}^{-}$trials were presented in each phase. An equal number of $\mathrm{CS}^{+}$and $\mathrm{CS}^{-}$trials were presented in the first and second half of fear acquisition and extinction training, respectively (fear acquisition training: 5 reinforced $\mathrm{CS}^{+}$and three nonreinforced $\mathrm{CS}^{+}$trials,
$8 \mathrm{CS}^{-}$trials; extinction training: $8 \mathrm{CS}^{+}$trials, $8 \mathrm{CS}^{-}$trials). Use of the two geometrical figures as $\mathrm{CS}^{+}$and $\mathrm{CS}^{-}$was counterbalanced within each group. $\mathrm{CS}^{+}$and $\mathrm{CS}^{-}$were presented in a pseudorandom order that was the same for all participants. The following restrictions were applied: (1) each CS was presented no more than two consecutive times; (2) the first two and last acquisition trials were reinforced $\mathrm{CS}^{+}$trials; and (3) the first two extinction trials were $\mathrm{CS}^{+}$trials.

The US (100 ms duration) was composed of four consecutive $500 \mu$ s current pulses. The transcutaneous shock was applied to the back of the right hand via a concentric bipolar surface electrode (WASP Electrode, Specialty Developments) using a constant current stimulator (DS7A, Digitimer; maximum output voltage, $400 \mathrm{~V}$ ). In reinforced trials, the US started $7.9 \mathrm{~s}$ after $\mathrm{CS}^{+}$onset and coterminated with the $\mathrm{CS}^{+}$(delay conditioning). The $\mathrm{CS}^{-}$was never followed by a US. Before the experiment, electric shock intensity was individually adjusted. Intensity was increased until perceived as uncomfortable but not painful (mean current, $6.22 \pm 3.56 \mathrm{~mA}$ ). To counteract habituation to the US leading to weakening of the CRs (i.e., inhibition with reinforcement; Burns and Kimmel, 1975), 20\% was added to the individual thresholds (mean added current, $1.24 \pm 0.71 \mathrm{~mA}$ ). Electric shock intensity was kept constant throughout the experiment. Participants, however, were allowed to ask for a decrease in intensity if needed. In two participants, intensity was decreased on request (by $10 \%$ and $15 \%$, respectively) after the first presentation of the US. At the beginning of the experiment, participants were instructed that should they perceive a pattern between stimuli that this pattern would not change throughout the experiment.

SCRs were obtained throughout the experiment using two SCR electrodes placed on the hypothenar of the left hand using electroconductive gel (GELLO Geltechnik). SCR data were bandpass filtered $(0.5-10 \mathrm{~Hz})$ to avoid high-frequency noise and low-frequency drifts. Raw SCRs were normalized through a logarithmic [ $\ln (1+\mathrm{SCR})]$ transformation. Processing of SCR data and semiautomated peak amplitude detection was performed using MATLAB software (releases 2017a and 2019a; MathWorks), followed by visual inspection and correction. SCRs were defined as the maximum trough-to-peak response amplitude within three predefined time windows (Prokasy and Ebel, 1967). Responses with an onset in the time window of 1.0-4.99 $\mathrm{s}$ after CS onset were defined as first interval response $\left(\mathrm{SCR}_{\mathrm{FIR}}\right)$, with an onset of 5.0-8.49 s after CS onset as second interval response (SCR $\mathrm{SIR}_{\mathrm{SI}}$, and with an onset of 8.5-13.0 s after CS onset as third interval response $\left(\mathrm{SCR}_{\mathrm{TIR}}\right.$; Fig. $2 A$; Jentsch et al., 2020).

Normalized data and the distribution of residuals were tested for normality using the Shapiro-Wilk test. Since the normality test revealed a non-normal distribution of SCRs and the residuals $(p<0.05)$, nonparametric statistical analysis was performed using the PROC Mixed procedure in SAS (SAS Studio 3.8, SAS Institute). SCRs were analyzed separately for fear acquisition training on day 1 and extinction training on day 2 using nonparametric ANOVAtype statistics for repeated measures (Brunner et al., 


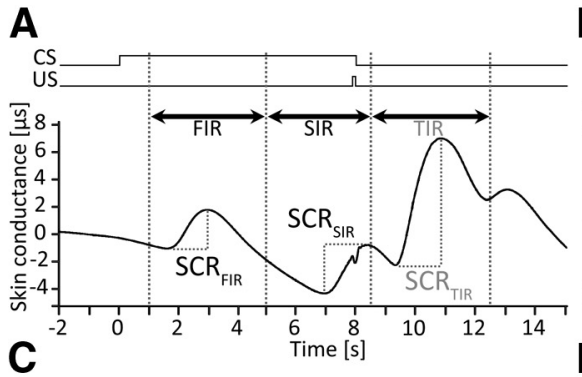

B
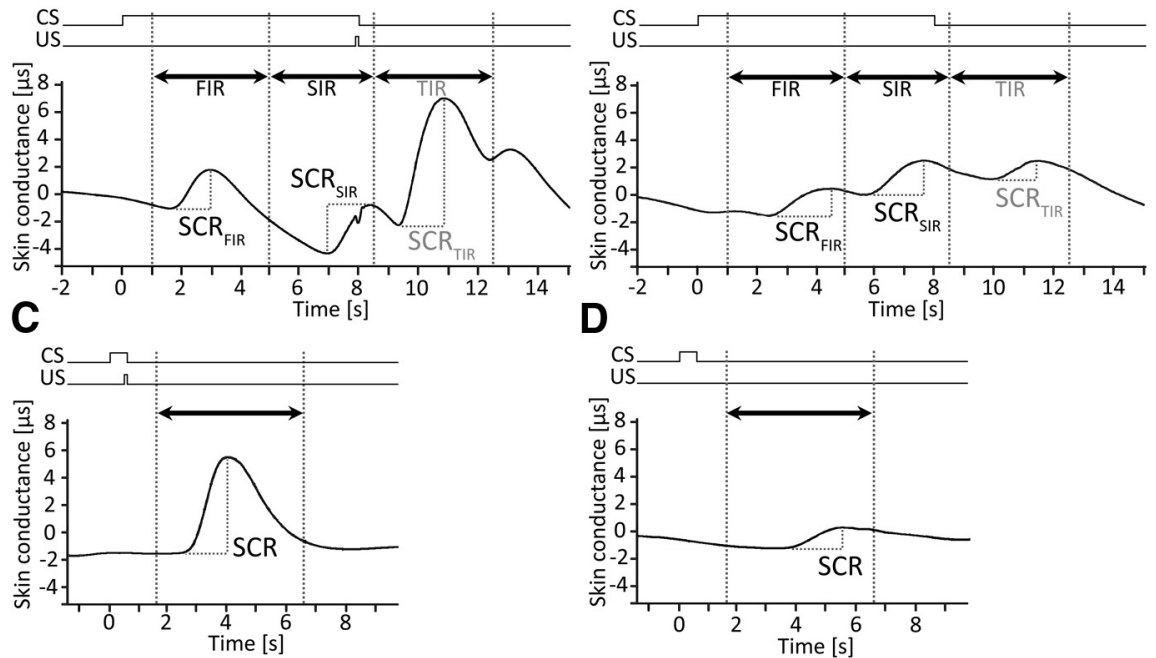

Figure 2. Examples of bandpass filtered individual SCRs. $\boldsymbol{A}, \boldsymbol{B}$, First, second, and third interval responses $\left(\mathrm{SCR}_{\mathrm{FIR}}, \mathrm{SCR}_{\mathrm{SIR}}, \mathrm{SCR}_{\mathrm{TIR}}\right)$ in a reinforced $\mathrm{CS}^{+}$fear acquisition training trial $(\boldsymbol{A})$ and an unreinforced $\mathrm{CS}^{+}$-only fear acquisition training trial $(\boldsymbol{B})$. Time windows of the first (1.0-4.99 s after CS onset), second (5.0-8.49 s after CS onset), and third (8.5-13.0 s after CS onset) interval responses are indicated by arrows and hatched lines. $\boldsymbol{C}, \boldsymbol{D}$, SCRs in a paired CS/US eyeblink acquisition trial (C) and an unpaired CS-only eyeblink acquisition trial $(\boldsymbol{D})$. SCR time window in eyeblink-conditioning trials (1-5 s after CS termination) is indicated by an arrow and hatched lines.

2002; Shah and Madden, 2004) with SCRs as dependent variable, group (groups 1-4) as a between-subject factor, and stimulus type $\left(\mathrm{CS}^{+}\right.$vs $\left.\mathrm{CS}^{-}\right)$and trial (16 trials) as within-subject factors. Post hoc pairwise comparisons were performed where appropriate using least-squares means tests.

To display individual data points and effect sizes, Cumming estimation plots (Cumming, 2012) were generated using the web application of DABEST ["data analysis with bootstrap-coupled estimation" (http://www.estimationstats. com/); Ho et al., 2019].

\section{Eyeblink conditioning}

A standard delay eyeblink-conditioning protocol was applied according to Gormezano and Kehoe (1975). The acquisition phase on day 1 consisted of 128 trials (80 paired CS/US trials with 48 CS-only trials interspersed; reinforcement rate, $62.5 \%$ ). The extinction phase on day 2 consisted of $32 \mathrm{CS}$-only trials. A neutral tone $(1 \mathrm{kHz}$; duration, $550 \mathrm{~ms}$ ) was used as CS and was presented to the right ear via earplugs using an AD229 Diagnostic Audiometer (Interacoustics). Before the experiment, participants were tested for individual hearing thresholds. CS intensity was set to $80 \mathrm{~dB}$. Ear defenders were used to reduce environmental noise. Participants wore an in housebuilt headband with an attached nozzle to apply an air puff as the US. The air puff (intensity, $400 \mathrm{kPa}$ at source, $110 \mathrm{kPa}$ at nozzle; duration, $100 \mathrm{~ms}$ ) was directed to the outer canthus of the right eye with $\sim 1 \mathrm{~cm}$ distance to the skin. US onset was set $450 \mathrm{~ms}$ after CS onset. The US coterminated with the CS. The ITI was $14 \pm 1.18 \mathrm{~s}$. Participants watched a silent nature movie during the eyeblink acquisition phase. They were instructed that they would need to answer questions about the video after the experiment to maintain vigilance.
EMG electrodes were attached to the lower eyelids and nose bridge to obtain signals from the orbicularis oculi muscles. The collected data were preamplified, rectified, and filtered (bandpass filter frequency, between $100 \mathrm{~Hz}$ and $5 \mathrm{kHz}$; gain, 2000; sampling rate, $1 \mathrm{kHz}$ ). EMG signals were semiautomatically analyzed with a custom-made software (Zuchowski et al., 2014). In each trial, CR onset was defined as the time when EMG reached $7.5 \%$ of maximum amplitude. Trials were visually inspected. Recordings erroneously identified as CRs by the algorithm were manually corrected, that is, artifacts caused by technical errors (e.g., detachment of the electrode) or movement (e.g., talking of the participant). EMG responses occurring within $150 \mathrm{~ms}$ after CS onset were considered as reflexive $(\alpha)$ responses to the tone and not rated as CRs (Gerwig et al., 2005). In paired CS/US trials, responses occurring between $150 \mathrm{~ms}$ after CS onset and US onset were rated as CRs. In CS-only trials, responses occurring between $150 \mathrm{~ms}$ after CS onset and CS termination were rated as CRs. If spontaneous blinks occurred $550 \mathrm{~ms}$ before CS onset, responses were not counted as CRs. Blocks of eight trials (five paired CS/US trials and three unpaired CS-only trials in the acquisition phase; eight unpaired CS-only trials in the extinction phase) were used to calculate the percentage of CR incidence per block. Latencies of CR onset and peak time, CR area, and $\mathrm{CR}$ duration were also analyzed as detailed in Extended Data Figures 5-3, 5-4, 5-5, and 5-6.

Nonparametric ANOVA-type statistics for repeated measures were used for statistical analysis. Analyses were performed separately for the acquisition and extinction phases with $\mathrm{CR}$ incidence as the dependent variable, group (groups 1, 2, 3, and 5) as the between-subject factor, and block (16 in acquisition; 4 in extinction) as the within-subject factor. Post hoc comparisons were performed using least-squares means tests. 

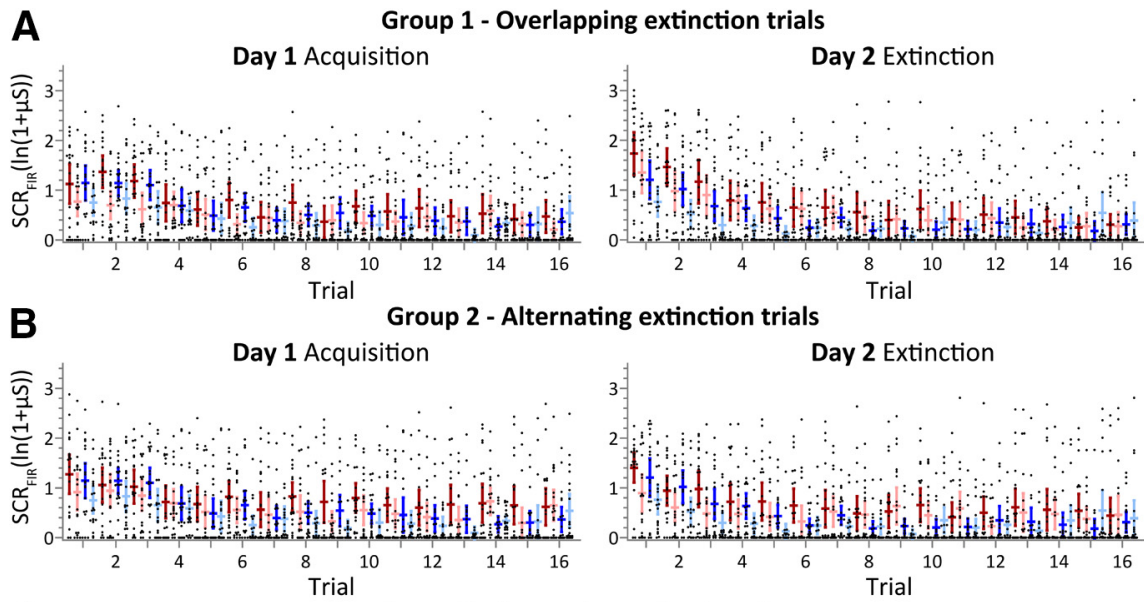

Day 2 Extinction
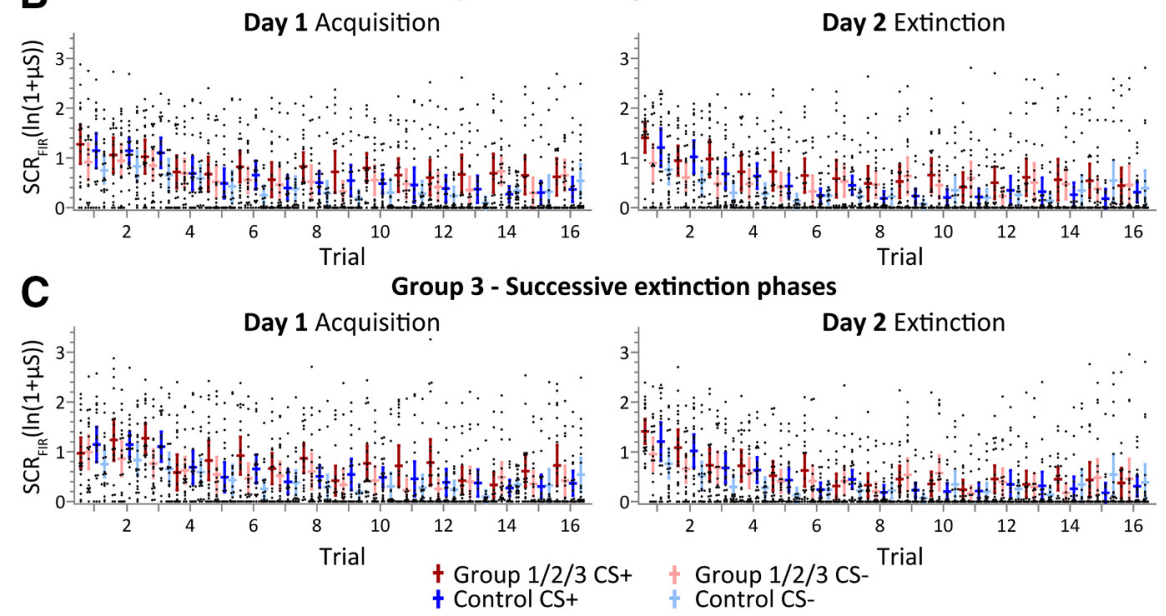

Figure 3. Fear-conditioning data. Group mean $\mathrm{SCR}_{\mathrm{FIR}}$ and individual data on day 1 (fear acquisition training) and day 2 (extinction training) across trials. $\boldsymbol{A}-\boldsymbol{C}$, Group 1 (overlapping extinction trials; shown in red) versus group 4 (control; shown in blue; $\boldsymbol{A}$ ); group 2 (alternating extinction trials; shown in red) versus group 4 (control; shown in blue; $\boldsymbol{B}$ ); and group 3 (successive extinction phases, shown in red) versus group 4 (control; shown in blue; C). Horizontal lines represent group mean values; vertical lines indicate 95\% confidence intervals. Black dots represent individual data points. See Extended Data Figure 3-1 for SCR SIR $_{\text {data. }}$

In addition, SCR data during eyeblink conditioning were analyzed. The maximum trough-to-peak-amplitude was calculated within a time window of 1-5 s following CS termination (Fig. 2C,D). During acquisition training, SCR data were analyzed separately for paired CS/US and unpaired CS-only trials, because SCR data are confounded by response to the US (air puff) in paired CS/US trials. Data of five consecutive CS/US trials and three consecutive CSonly trials were averaged, resulting in $16 \mathrm{CS} / \mathrm{US}$ and 16 CS-only blocks. During extinction training, SCR data were averaged across eight consecutive trials, resulting in four blocks. Nonparametric ANOVA-type statistics for repeated measures was calculated separately for paired and unpaired trials in acquisition training, and for unpaired trials in extinction training with SCR as the dependent variable, group (groups 1, 2, 3, 5) as the between-subject factor, and block (16 in acquisition; 4 in extinction) as the within-subject factor.

\section{Fear-conditioning questionnaires}

Participants were required to answer questionnaires before and after fear acquisition training, and after fear extinction training. The questionnaires were print copies. Participants were required to rate valence and arousal to images of the $\mathrm{CS}^{+}$and $\mathrm{CS}^{-}$on a 9-point Likert scale to assess the affective components of learning (for review, see Lonsdorf et al., 2017). The scale went from "very pleasant" and "calm" to "very unpleasant" and "very excited," respectively. The valence and arousal ratings were compared using nonparametric ANOVA-type statistics for repeated measures with the self-reported valence or arousal score as the dependent variable, group (groups 1 , 2,3 , and 4) as the between-subject factor, and time (prior acquisition, postacquisition, post extinction) as the within-subject factor. Postacquisition training, participants were asked to rate US unpleasantness on a 9-point Likert scale from not unpleasant to very unpleasant, and to estimate the mean probability that a US occurred after presentation of the $\mathrm{CS}^{+}$(i.e., CS/US contingency). Unpleasantness of the US was rated after fear acquisition training to control for possible effects of habituation and sensitization (for review, see Lonsdorf et al., 2017). Differences between groups were analyzed using nonparametric ANOVA-type statistics.

\section{Results}

\section{Fear conditioning}

Acquisition phase (day 1)

$\mathrm{SCR}_{\mathrm{FIR}}$ values were significantly higher in $\mathrm{CS}^{+}$trials compared with $\mathrm{CS}^{-}$trials in all groups (Fig. $3 A-C$ ). Nonparametric ANOVA-type statistics revealed a significant main effect of trial (trials $1-16 ; F_{(11.2)}=29.18$, $p<0.001$ ), stimulus type $\left(\mathrm{CS}^{+}\right.$vs $\mathrm{CS}^{-} ; F_{(1)}=24.91$, $p<0.001)$, and a significant trial $\times$ stimulus type interaction $\left(F_{(12.1)}=5.95, p<0.001\right)$. No significant main effects of group $(p=0.64)$, group $\times$ stimulus $(p=0.87)$, group $\times$ trial interaction $(p=0.66)$, or group $\times$ stimulus $\times$ trial $(p=0.86)$ were revealed. Similar findings were observed 

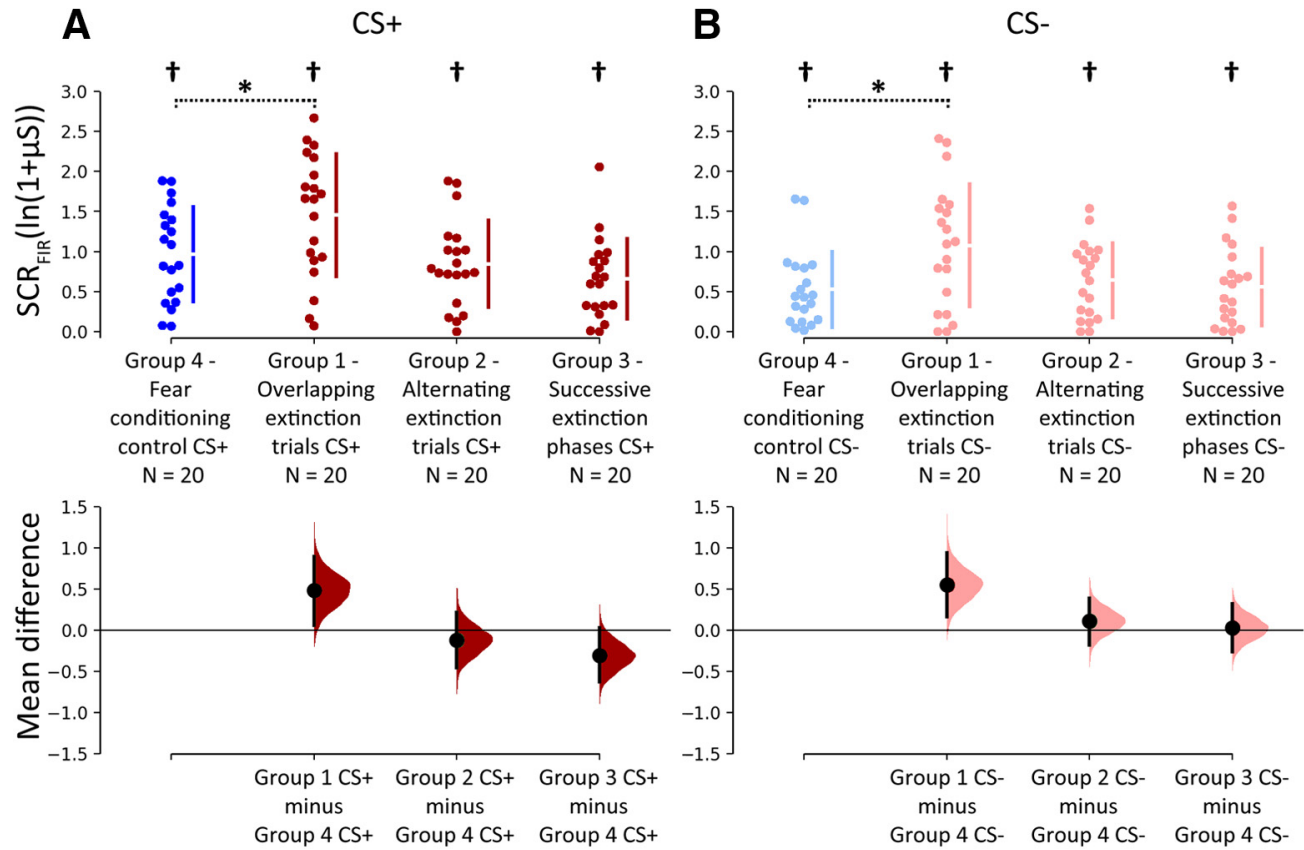

Figure 4. Recall of learned fear responses for $\mathrm{SCR}_{\mathrm{FIR}}$ at the beginning of extinction training. $\boldsymbol{A}, \boldsymbol{B}$, Cumming estimation plots showing mean differences between groups 1 and 3 (shown in red) and the control group 4 (shown in blue) averaged across the first three extinction trials of $\mathrm{CS}^{+}(\boldsymbol{A})$ and $\mathrm{CS}^{-}(\boldsymbol{B}) \mathrm{SCR}_{\mathrm{FIR}}$. Top, Dots represent individual data points. Gapped lines indicate group means (gap) and SDs. Bottom, Effect sizes. Black dots represent the mean differences between groups, and error bars indicate $95 \%$ Cls. 95\% Cls are calculated by bootstrap resampling (Ho et al., 2019). Filled curves represent the bootstrap sampling distribution of the observed data. Dark colors, $\mathrm{CS}^{+}$; light colors, $\mathrm{CS}^{-}$. *Significant differences between respective stimuli between group 1 and group 4 (control; Mann-Whitney $U$ tests, $p$ values $<0.05$ ). †Significant SCR $_{\mathrm{FIR}}$ differences between $\mathrm{CS}^{+}$and $\mathrm{CS}^{-}$in the same group

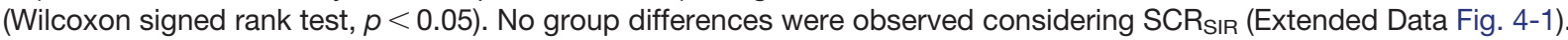

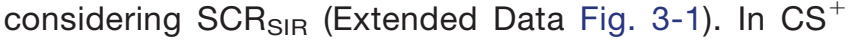
trials, no significant group differences and interactions were observed regarding SCRs in the $\mathrm{SCR}_{\mathrm{TIR}}$ (all $p$ values $>0.42)$.

\section{Extinction phase (day 2)}

$\mathrm{SCR}_{\mathrm{FIR}}$ values were higher in $\mathrm{CS}^{+}$trials compared with $\mathrm{CS}^{-}$trials in all groups at the beginning of extinction training. This difference disappeared in later trials (Fig. $3 A-C$ ). Nonparametric ANOVA-type statistics revealed a significant main effect of trial (trials $1-16 ; F_{(9.73)}=30.91$, $p<0.001)$, stimulus type $\left(\mathrm{CS}^{+}\right.$vs $\mathrm{CS}^{-} ; F_{(1)}=47.95$, $p<0.001$ ), and a significant trial $\times$ stimulus type interaction $\left(F_{(11.5)}=1.93, p=0.0301\right)$. The group $\times$ trial interaction did not reach significance $\left(F_{(1)}=29.2, p=0.064\right)$. The group main effect $(p=0.52)$, the group $\times$ stimulus interaction $(p=0.75)$ and the group $\times$ stimulus $\times$ trial interaction $(p=0.12)$ were not significant.

Closer inspection of Figure 3 showed that SCR $_{\mathrm{FIR}}$ values in the initial $\mathrm{CS}^{+}$and $\mathrm{CS}^{-}$trials, that is, during recall of learned fear responses, were higher in group 1 (overlapping extinction trials) compared with the control group 4 , but not in group 2 (alternating extinction trials) and group 3 (successive extinction phases) compared with the control group 4. This difference is further illustrated in Figure 4 showing $\mathrm{SCR}_{\mathrm{FIR}}$ averaged across the first three extinction trials. Mann-Whitney $U$ tests revealed significant differences between groups 1 and $4\left(\mathrm{CS}^{+}: U=122, z\right.$ $=-2.110, p=0.035 ; \mathrm{CS}^{-}: U=123, z=-2.083, p=0.037$ ), but no significant differences comparing group 2 and group $4\left(\mathrm{CS}^{+}: U=177, z=-0.622, p=0.53 ; \mathrm{CS}^{-}: U=157\right.$, $z=-0.927, p=0.35)$, and group 3 and group $4\left(\mathrm{CS}^{+}\right.$: $U=184, z=-0.433, p=0.67$; SS $^{-}: U=148, z=-1.407$, $p=0.16)$. No group differences were observed consider-

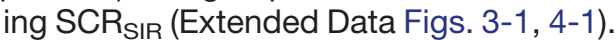

\section{Eyeblink conditioning}

\section{CR incidence}

Acquisition phase (day 1). Figure 5 shows the mean percentage and $95 \%$ confidence intervals (Cls) of CR incidences across the 16 acquisition and 8 extinction blocks in the four groups. In the acquisition phase, a significant increase in CR incidence was observed in all groups. Taking all participants $(n=80)$ together, the mean \pm SD percentage of CR incidence increased from $23.91 \pm 25.01 \%$ in the first acquisition block to $48.44 \pm 31.1 \%$ in the last acquisition block. Nonparametric ANOVA-type statistics revealed a significant effect of block $\left(F_{(9.7)}=15.10 ; p<0.0001\right)$, but no group $(p=0.59)$ or group $\times$ block interaction effects $(p=0.45)$.

Closer inspection of Figure 5 revealed that CR incidence was higher in the three groups that had received prior fear conditioning (groups 1-3, indicated in green) compared with the control group (group 5, indicated in yellow). This difference was most marked in the first three acquisition blocks. Nonparametric ANOVA-type statistics performed in individual blocks revealed significant group differences in the first block only (block 1: $F_{(3)}=3.87$, 
A Group 1 - Overlapping extinction trials

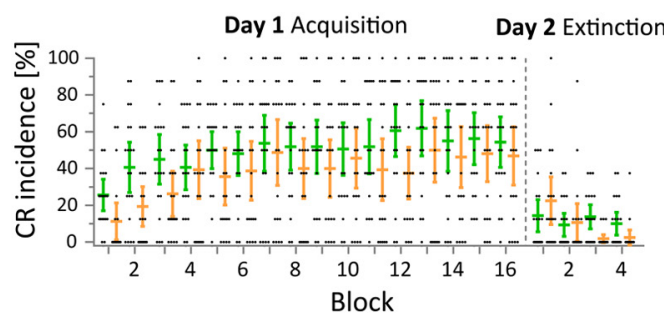

C Group 3 - Successive extinction phases

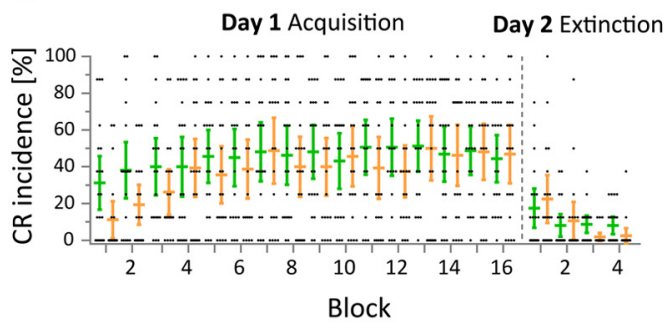

+ Group 1/2/3 + Eyeblink control

\section{B Group 2 - Alternating extinction trials}

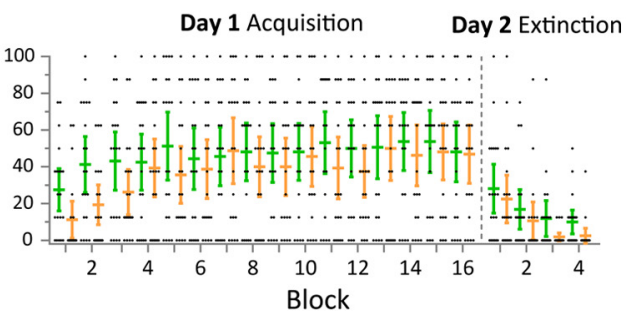

Figure 5. Eyeblink conditioning: group mean percentage CR incidences and individual data shown in the acquisition phase on day 1 (16 blocks and 8 trials), and in the extinction phase on day 2 (4 blocks and 8 trials). $\boldsymbol{A}-\boldsymbol{C}$, Group 1 (overlapping extinction trials; shown in green) versus group 5 (control; shown in yellow; $\boldsymbol{A}$ ); group 2 (alternating extinction trials; shown in green) versus group 5 (control; shown in yellow; $\boldsymbol{B}$ ); and group 3 (successive extinction phases; shown in green) versus group 5 (control; shown in yellow; C). Horizontal lines represent mean values, vertical lines indicate 95\% confidence intervals. Black dots show individual data points. CR incidences for the first four acquisition blocks are shown in Extended Data Figure 5-1. Trial-by-trial analysis of the first acquisition and extinction blocks are shown in Extended Data Figure 5-2. Latencies of CR onset and peak time, and CR area and CR duration are presented in Extended Data Figures 5-3, 5-4, 5-5, and 5-6.

$p=0.0124 ;$ block 2: $F_{(3)}=2.51, p=0.065 ;$ block 3: $F_{(3)}=$ $1.49, p=0.26$; blocks $4-10, p>0.41$ ). Post hoc pairwise comparisons revealed significantly increased CR incidence in groups 1, 2, and 3 compared with that in group 5 (control) during the first acquisition block (least-squares means tests, all $p$ values $<0.0086$; Extended Data Fig. 51). The difference between control and experimental groups is further illustrated in Extended Data Figure 5-2, showing a trial-by-trial analysis of the first acquisition block, and in Figure 6, showing EMG eyeblink traces of individual participants from each group.

Closer inspection of EMG eyeblink traces in Figure 6 showed that responses occurred earlier in the three groups having received prior fear learning, compared with control participants, and responses sustained until US onset. CR onset and peak time latencies showed a high degree of variability within individual participants and were not significantly different between groups (group effects, group $\times$ block interaction effects: all $p$ values $>0.48$; Extended Data Figs. 5-3, 5-4). In CS-only trials, nonparametric ANOVAtype statistics with $\mathrm{CR}$ duration as the dependent variable revealed significant effects of group and group $\times$ block interaction (all $p$ values $<0.0167$ ); the block effect was not significant $(p=0.0708)$. In CS/US trials, no significant main effects of block, group or a group $\times$ block interaction were revealed (all $p$ values $>0.28$; Extended Data Fig. 5-5). CR area was also significantly different between groups in CSonly trials $(p=0.0015)$, but not in CS/US trials $(p=0.0788)$; main effects of block and group $\times$ block interaction were not significant (all $p$ values $>0.23$; Extended Data Fig. 5-6).
Extinction phase (day 2). In the extinction phase, CR incidence decreased significantly in all groups (Fig. 5). Considering all participants together, the mean CR incidence decreased from $20.63 \pm 24.77 \%$ in the first extinction block to $7.65 \pm 11.85 \%$ in the last extinction block. During late extinction (extinction blocks 3-4), mean CR incidences were higher in groups 1-3 (Fig. 5, indicated in green) compared with group 5 (Fig. 5, control, indicated in yellow). Nonparametric ANOVA-type statistics revealed a significant main effect of block $\left(F_{(2.73)}=7.42 ; p<0.0002\right)$. No significant main effect of group or group $\times$ block interaction were revealed $(p>0.08)$.

Post hoc nonparametric ANOVA-type statistics comparing $C R$ incidence in early extinction (trials 1-16) with late extinction (trials 17-32) revealed a significant main effect of block (early vs late; $F_{(1)}=12.53 ; p=0.0007$ ), and a significant group $\times$ block interaction $\left(F_{(3)}=3.76 ; p=\right.$ $0.0143)$. The group effect was not significant $(p=0.12)$. Post hoc pairwise comparisons comparing early and late extinction revealed a significant CR reduction in group 2 $(22.5 \pm 22.16 \%$ to $10.94 \pm 16.21 \%$; least squares means test, $p=0.0139)$ and the control group $5(16.56 \pm 22.51 \%$ to $2.19 \pm 5.08 \%$; least squares means test, $p=0.0001$ ), but not in groups 1 and 3 (least squares means tests, $p$ values $>0.45$ ). Post hoc pairwise comparisons between groups revealed higher mean CR incidence in late extinction in groups 1,2 , and $3(11.88 \pm 12.65 \%, 22.5 \pm$ $22.16 \%$, and $12.81 \pm 13.97 \%$, respectively) compared with control group $5(2.19 \pm 5.08 \%$, least squares means tests, all $p$ values $<0.0063$ ). No significant differences 


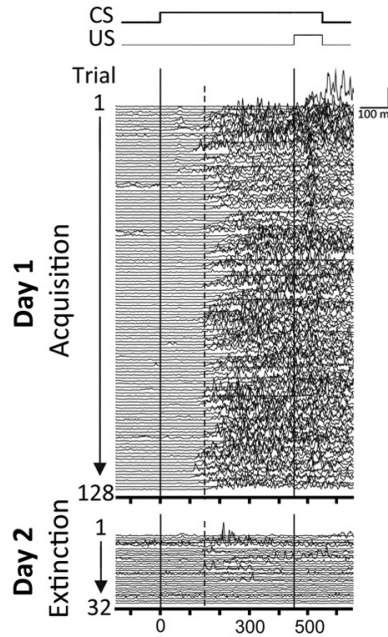

Group 1 -

Overlapping

extinction

trials

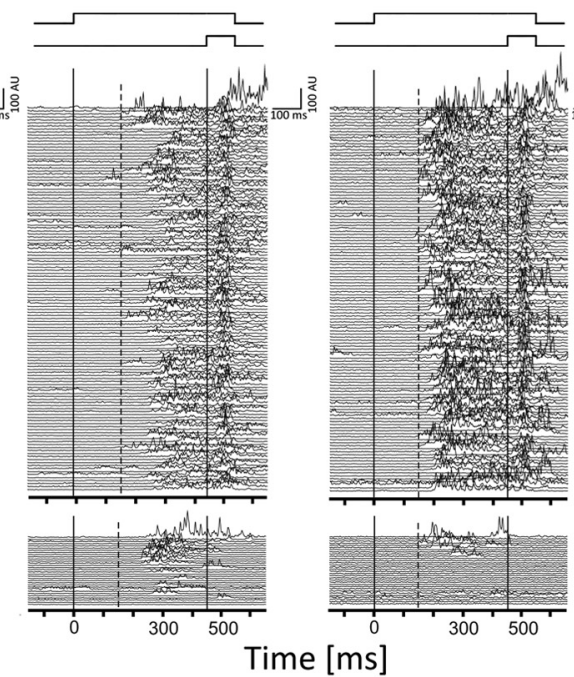

Group 2 -

Alternating

extinction

trials
Group 3 -

Successive

extinction

phases

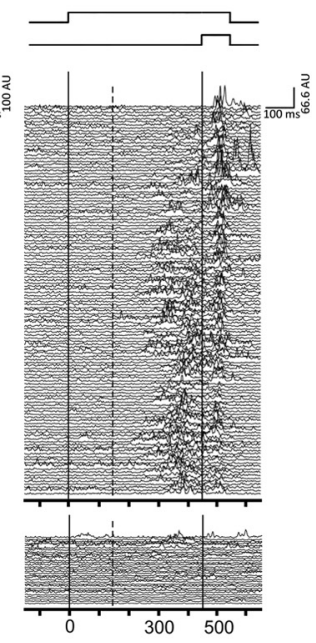

Group 5 -

Eyeblink

conditioning

control

Figure 6. EMG eyeblink traces of individual participants from each group (groups 1, 2, 3, and 5). Rectified and filtered (100 Hz) EMG data of the orbicularis oculi muscle of 80 paired CS/US and 48 CS-only trials on day 1 (acquisition training) and 32 CS-only trials on day 2 (extinction training). The first (solid) vertical line indicates the beginning of the tone (CS), and the second (solid) vertical line indicates the beginning of the air puff (US). Responses occurring within the $150 \mathrm{~ms}$ interval after CS onset (dotted vertical line) were considered $\alpha$ blinks. AU, Arbitrary unit.

were found in early extinction (least squares means tests, all $p$ values $>0.28$; Fig. 7 ).

In the extinction phase, CR onset and peak time latencies, and CR area were not significantly different between groups (group effects, group $\times$ block interaction effects: all $p$ values $>0.14$; Extended Data Figs. 5-3, 5-4, 5-6). Nonparametric ANOVA-type statistics considering CR duration revealed a significant main effect of group $\left(F_{(2.79)}\right.$ $=3.89 ; p=0.0157$ ); the effects of block and group $\times$ block interaction were not significant (all $p$ values $>0.16$; Extended Data Fig. 5-5).

\section{Skin conductance responses}

Acquisition phase (day 1). As expected, SCR analysis revealed higher SCR peak amplitudes in CS/US paired trials compared with CS-only trials during early acquisition blocks in all groups (Fig. 8). This difference decreased in later blocks. In CS/US paired and CS-only trials, SCR peak amplitudes tended to be higher in groups 1-3 compared with group 5 (Fig. 8, control, indicated in yellow). This difference was most prominent at the end of fear acquisition training. Considering paired CS/US trials, nonparametric ANOVA-type statistics revealed a significant main effect of block $\left(F_{(8.23)}=40.52, p<0.0001\right)$ and block $\times$ group interaction $\left(F_{(24.6)}=1.79, p=0.0114\right)$. Considering CS-only trials, nonparametric ANOVA-type statistics revealed a significant main effect of block $\left(F_{(10.8)}=\right.$ $16.0, p<0.0001)$ and a significant block $\times$ group interaction $\left(F_{(32.4)}=1.63, p=0.0156\right)$. No significant main effects of group (paired: $p=0.15$; unpaired: $p=0.25$ ) were revealed. Post hoc comparisons revealed significantly higher SCR peak amplitudes in group 1, 2, and 3 compared with the control group considering the following acquisition blocks: paired trials: group 1, blocks 1,11 , and 13-15; group 2, blocks 10, 11, 13, 15, and 16; group 3, blocks 1 and 14-16; unpaired trials: group 1, blocks 1416; groups 2 and 3 , blocks 15 and 16 (least squares means tests, all $p$ values $<0.0477$ ).

Extinction phase (day 2). SCRs during extinction training were significantly higher in groups 1,2 , and 3 compared with the control group 5 (Fig. 8). This difference was most prominent in the first extinction block. Nonparametric ANOVA-type statistics revealed a significant main effect of block $\left(F_{(2.56)}=38.31, p<0.0001\right)$ and group $\left(F_{(2.99)}=2.78\right.$, $p=0.0475)$, and a significant block $\times$ group interaction $\left(F_{(7.65)}=2.56, p=0.0127\right)$. Post hoc comparisons revealed significantly higher SCRs comparing groups 2 and 3 with the control group 5 (least squares means tests, all $p$ values $<0.046$ ) and a close to significant difference comparing groups 1 and 5 (least squares means test, $p=0.0511$ ). Pairwise group $\times$ block comparisons of groups 1,2 , and 3 with the control group 5 revealed significantly higher SCRs in the following blocks: group 1 versus 5 , block 4; group 2 versus 5, blocks 1, 2, 4; group 3 versus 5, blocks 1, 2 (least squares means tests, all $p$ values $<0.049$ ).

\section{Fear conditioning questionnaires}

Valence. Prior acquisition training and valence ratings of the $\mathrm{CS}^{+}$and $\mathrm{CS}^{-}$were not significantly different from each other (Table 1). Post-acquisition training, valence of the $\mathrm{CS}^{+}$was rated as less pleasant compared with the $\mathrm{CS}^{-}$. A small difference in valence ratings remained post- 


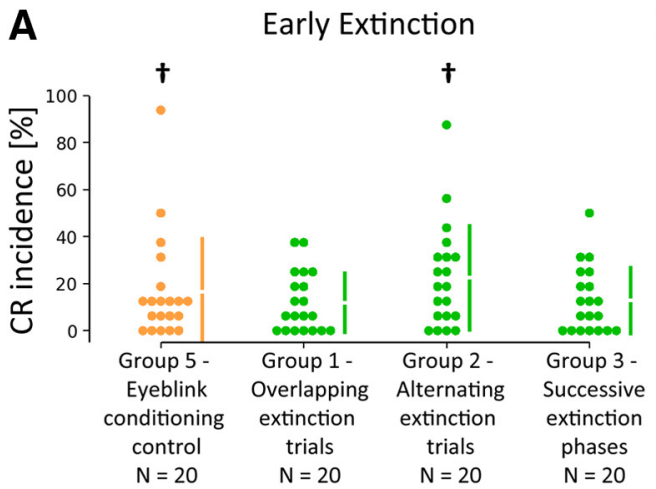

B
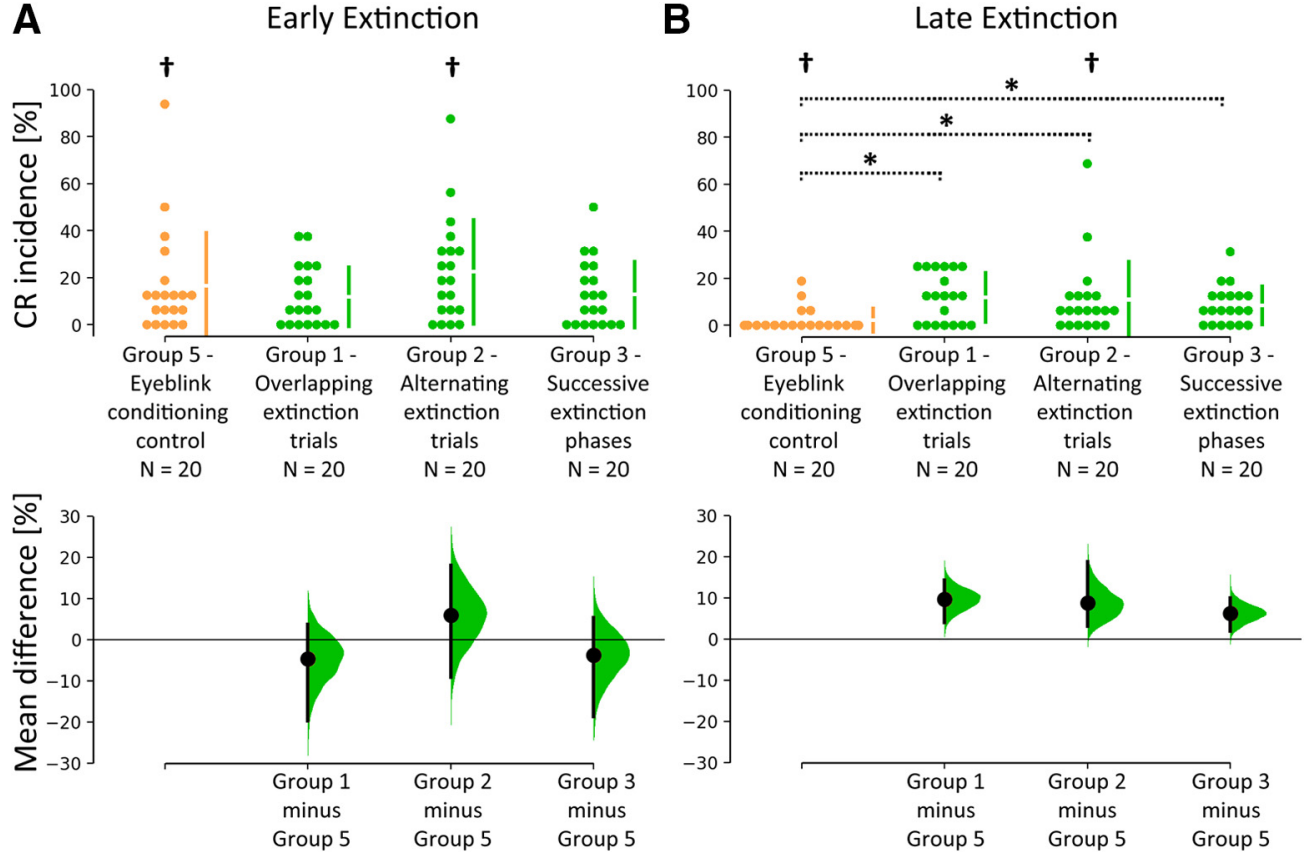

Figure 7. $\mathrm{CR}$ incidences in early and late extinction. $\boldsymbol{A}, \boldsymbol{B}$, Cumming estimation plot showing mean differences between groups 1 and 3 (shown in green) and control group 5 (shown in yellow) for early $(\boldsymbol{A})$ and late $(\boldsymbol{B})$ extinction (blocks in 16 trials). Top, Dots represent individual data points. Gapped lines indicate group means (gap) and SDs. Bottom, Effect sizes. Black dots represent mean differences between groups, and error bars indicate $95 \% \mathrm{Cls} .95 \% \mathrm{Cl}$ are calculated by bootstrap resampling (Ho et al., 2019). Filled curves represent the bootstrap sampling distribution of the observed data. $*$ Significant differences between respective stimuli between Groups 1, 2, and 3 and group 5 (least squares means tests, $p$ values $<0.05$ ). †Significant CR differences between early and late extinction in the same group (least square means tests, $p<0.05$ ).

extinction training (a finding frequently seen in the literature; e.g., Ernst et al., 2019). There was no difference between groups [group 1,2,3, and group 4 (control)]. Nonparametric ANOVA-type statistics revealed a significant main effect of time (prior acquisition vs post-acquisition vs post-extinction training: $\left.F_{(1.84)}=4.03, p=0.023\right)$, stimulus $\left(\mathrm{CS}^{+}\right.$vs $\left.\mathrm{CS}^{-}: F_{(1)}=81.56, p<0.0001\right)$, and a stimulus $\times$ time interaction $\left(F_{(1.91)}=48.68, p<0.0001\right)$. The group main effect $(p=0.9)$, the group $\times$ stimulus interaction $(p=0.9)$, and the group $\times$ stimulus $\times$ time interaction $(p=0.35)$ were not significant. Post hoc tests showed significantly less pleasant valence rating toward $\mathrm{CS}^{+}$than $\mathrm{CS}^{-}$post-acquisition and post-extinction training (least squares means tests, all $p$ values $<0.0002$ ), but not prior acquisition training (least squares means test, $p=0.6$ ). Valence ratings toward the $\mathrm{CS}^{+}$post-acquisition training were rated significantly less pleasant compared with prior acquisition training, with the $\mathrm{CS}^{-}$ratings showing the opposite effect (least square means tests, all $p$ values $<0.0001$ ).

Arousal. Prior acquisition training, arousal ratings of the $\mathrm{CS}^{+}$and $\mathrm{CS}^{-}$were not different from each other (Table 1). Post-acquisition, arousal toward the $\mathrm{CS}^{+}$was rated higher compared with the $\mathrm{CS}^{-}$. A small difference in valence ratings remained post-extinction. There was no difference between groups [group 1, 2, and 3, and group 4 (control)]. Nonparametric ANOVA-type statistics revealed a significant main effect of time (prior acquisition vs post-acquisition- vs post-extinction training; $F_{(1.71)}=$ 5.33, $p=0.009)$, Stimulus $\left(\mathrm{CS}^{+}\right.$vs $\mathrm{CS}^{-} ; F_{(1)}=56.72$, $p<0.0001)$ and stimulus $\times$ time interaction $\left(F_{(1.94)}=\right.$
33.34, $p<0.0001)$. The group main effect $(p=0.49)$, the group $\times$ stimulus interaction $(p=0.86)$, and group $\times$ stimulus $\times$ time interactions $(p=0.94)$ were not significant. Post hoc tests showed significantly higher arousal ratings toward $\mathrm{CS}^{+}$than $\mathrm{CS}^{-}$post-acquisition training and post-extinction training (least squares means tests, all $p$ values $<0.0001$ ), but not prior acquisition training (least square means test, $p=0.55)$. Arousal toward the $\mathrm{CS}^{+}$post-acquisition training was rated significantly higher compared with prior acquisition training, whereas arousal toward $\mathrm{CS}^{-}$was rated significantly less compared with prior acquisition training (least square means tests, all $p$ values $<0.0004$ ).

US unpleasantness and CS-US contingency. Post-acquisition training, the median US unpleasantness rating was 7 (IQR, 6-8) on a Likert scale from 1 (not unpleasant) to 9 (very unpleasant) considering all participants. There was no significant difference between groups (nonparametric ANOVA-type statistic, $p=0.13$ ). Post-acquisition training, participants reported that they recognized a pattern between $\mathrm{CS}^{+}$and US contingency after $2.9 \pm$ $1.4 \mathrm{~min}$. Across all participants, the mean probability that a US occurred after presentation of the $\mathrm{CS}^{+}$was estimated as $63.9 \pm 17.8 \%$, and after presentation of the $\mathrm{CS}^{-}$ as $2.53 \pm 7.8 \%$ [0\% probability by 68 of $80(85 \%)$ participants]. There was no significant difference between groups (nonparametric ANOVA-type statistic, $p=0.39$ ).

\section{Discussion}

The concomitant presentation of eyeblink- and fear-conditioning stimuli did not facilitate extinction learning but 

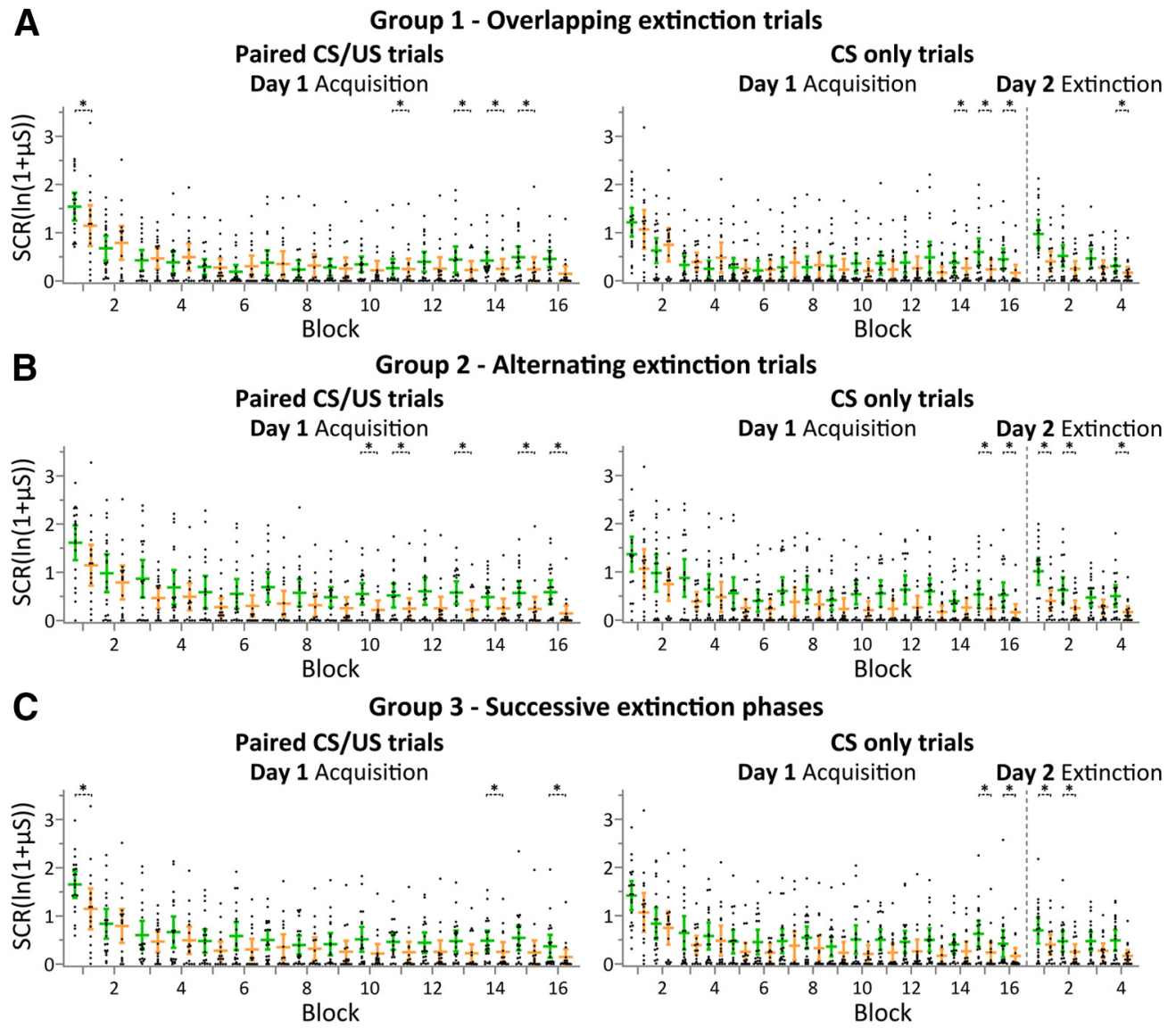

+ Group $1 / 2 / 3 \quad+$ Eyeblink control

Figure 8. Eyeblink conditioning: group mean SCRs per block and individual data during eyeblink acquisition training in paired CS/ US trials (5 trials/block), during eyeblink acquisition training in CS-only trials ( 3 trials/block), and during eyeblink extinction training in CS-only trials (8 trials/block). $\boldsymbol{A}-\boldsymbol{C}$, Group 1 (overlapping extinction trials; shown in green) versus group 5 (control; shown in yellow; $\boldsymbol{A})$; group 2 (alternating extinction trials; shown in green) versus group 5 (control; shown in yellow; $\boldsymbol{B}$ ); and group 3 (successive extinction phases; shown in green) versus group 5 (control; shown in yellow; $\boldsymbol{C}$ ). Horizontal lines represent mean values, and vertical lines indicate $95 \% \mathrm{Cls}$. Black dots show individual data points. $*$ Significant differences between respective stimuli between groups 1,2 , and 3 and group 5 (least squares means tests, $p$ values $<0.05$ ).

facilitated recall of previously learned fear responses. Furthermore, the extinction of conditioned eyeblink responses was impeded and was accompanied by increased autonomic fear responses. Findings do not support the hypothesis that conditioned eyeblink responses, once established, suppress conditioned fear responses (Magal and Mintz, 2014). The possible interactions between eyeblink and fear conditioning are discussed in more detail below.

Table 1: Fear-conditioning questionnaires

\begin{tabular}{|c|c|c|c|c|c|c|c|c|}
\hline \multirow[b]{2}{*}{ Time of assessment } & \multicolumn{2}{|c|}{$\begin{array}{l}\text { Group } 1-\text { overlapping } \\
\text { extinction trials }\end{array}$} & \multicolumn{2}{|c|}{$\begin{array}{c}\text { Group 2-alternating } \\
\text { extinction trials }\end{array}$} & \multicolumn{2}{|c|}{$\begin{array}{c}\text { Group 3-successive } \\
\text { extinction phases }\end{array}$} & \multicolumn{2}{|c|}{$\begin{array}{c}\text { Group 4-fear } \\
\text { conditioning control }\end{array}$} \\
\hline & $\mathrm{CS}^{+}$ & $\mathrm{CS}^{-}$ & $\mathrm{CS}^{+}$ & $\mathrm{CS}^{-}$ & $\mathrm{CS}^{+}$ & $\mathrm{CS}^{-}$ & $\mathrm{CS}^{+}$ & $\mathrm{CS}^{-}$ \\
\hline \multicolumn{9}{|c|}{ Valence ratings ( 1, uncomfortable; 9 , comfortable) } \\
\hline Prior acquisition & $5(5-6)$ & $5(5-7)$ & $5.5(5-7)$ & $5.5(5-7)$ & $5(5-6.25)$ & $5(5-7)$ & $5(5-7)$ & $5(5-7)$ \\
\hline Post-acquisition training & $3(2.75-5) * \dagger$ & $7(6.75-8.25) * \dagger$ & $3.5(2-5) * \dagger$ & $7.5(6-9) * \dagger$ & $4(3-5) * \dagger$ & $7(6-8.25) * \dagger$ & $4(3-5) * \dagger$ & $7(6-8.25) * \dagger$ \\
\hline Post-extinction training & $5(3-7)^{*}$ & $7(5.75-7.25) * \dagger$ & $5(5-6.25)^{*}$ & $7(5-8) * \dagger$ & $5(5-7)^{*}$ & $7(5-8) * \dagger$ & $5(5-7)^{*}$ & $6.5(5-8) * \dagger$ \\
\hline \multicolumn{9}{|c|}{ Arousal ratings (1, calm; 9 , excited) } \\
\hline Prior acquisition & $3(1-5)$ & $2.5(1-5)$ & $3.5(2-5)$ & $3(2-5)$ & $3(1-5)$ & $2.5(1-5)$ & $3.5(2-5)$ & $5(1.75-5)$ \\
\hline Post-acquisition training & $5.5(3.75-7) * \dagger$ & $2(1-3) * \dagger$ & $5(4.5-7) * \dagger$ & $1.5(1-3) * \dagger$ & $6(3-7) * \dagger$ & $1(1-3.25) * \dagger$ & $5(4.5-7) * \dagger$ & $2(1-4.25) * \dagger$ \\
\hline Post-extinction training & $3.5(2.75-6)^{*}$ & $3(1.75-3.25) * \dagger$ & $4(2-5)^{*}$ & $2(1-3) * \dagger$ & $3(1-5)^{*}$ & $2(1-5) * \dagger$ & $4(2-5)^{*}$ & $2.5(1-5) * \dagger$ \\
\hline
\end{tabular}

Self-reported median (IQR) valence and arousal ratings prior acquisition training, post-acquisition training and post-extinction training. Statistical significances $(p<0.5)$ are indicated in bold.

* Significant differences between pre-acquisition training and post-acquisition training.

+ Significant differences between $\mathrm{CS}^{+}$and $\mathrm{CS}^{-}$(least squares means tests, $p<0.05$ ). 
The amygdala is critically involved in the acquisition and retention of learned fear responses (Weisz et al., 1992; Rogan et al., 1997; Rosenkranz et al., 2003; Schroeder and Shinnick-Gallagher, 2005; Butler et al., 2018). The extinction of learned fear requires inhibition of the amygdala (Amano et al., 2010; Herry et al., 2010; Krabbe et al., 2018). Thus, in case the assumption is correct that conditioned eyeblink responses lead to inhibition of the amygdala (Magal and Mintz, 2014), concomitant conditioned eyeblinks should reduce recall and accelerate extinction of conditioned fear responses. This was not the case. The concomitant presentation of conditioned eyeblink and fear stimuli had no significant impact on fear extinction learning. However, overlapping CSs resulted in increased recall of conditioned fear responses. The increase was most marked for SCRs in the FIR window (1$4.99 \mathrm{~s}$ following CS onset). This agrees with findings that conditioning-related changes of SCR amplitudes are most prominent in the first 3-4 s following CS onset (Pineles et al., 2009; Jentsch et al., 2020). It has been argued that FIRs reflect orienting or novelty responses (Ohman, 1972, 1974). Other studies suggest that FIRs are also related to associative processes, in particular during extinction (Jentsch et al., 2020). Increased recall of learned fear responses is in good agreement with the phenomenon of additive response summation: following individual conditioning for two different CSs, the compound presentation of the two CSs results in a CR that is the sum of the responses to each of the individual CSs (Hull, 1943; Kimble, 1961; Wolf, 1963; Weiss, 1964, 1972; Miller, 1969). The response increase is most obvious when CSs from different modalities are used to learn the same response (Pérez et al., 2018). In the present study, a visual fear CS and a tone eyeblink CS were used. Both result in conditioned fear responses. Additive response summation suggests that fear responses accompanying initial eyeblink conditioning are not fully suppressed after the specific aversive motor response has been developed. In fact, Lindquist et al. (2010) also provided evidence that fear conditioning in eyeblink conditioning is an autonomous learning process that is not turned off when conditioned eyeblink responses have been acquired. They found that preceding eyeblink conditioning resulted in facilitated acquisition of conditioned fear and increased conditioned fear responses.

As expected, prior fear conditioning accelerated the acquisition of conditioned eyeblink responses, accompanied by increased autonomic fear responses. Findings were most obvious in the first conditioning block. This agrees with the observation that learning occurs mainly in the first block of 10 conditioning trials in humans (Kjell et al., 2018). Previous findings on accelerated eyeblink conditioning are based on experiments using the same CS in fear conditioning preceding eyeblink conditioning in rodents (Neufeld and Mintz, 2001). The present findings extend the effects of preceding fear conditioning to CSs from two different modalities in humans. Accompanying autonomic responses decreased during eyeblink conditioning, which is also in line with the previous literature (Neufeld and Mintz, 2001).
In addition, prior fear conditioning resulted in changes of the topography of the conditioned responses. Responses were longer lasting, and frequently occurred at a shorter latency (Fig. 6), although the latter was not significant. Long-lasting, short-latency responses are well known in mouse eyeblink conditioning, and are thought to be at least partially driven by the amygdala (and not the cerebellum; Boele et al., 2010). Conditioned responses, on the other hand, showed some resemblance to responses that were discussed as being volitional in the early human eyeblink conditioning literature (for review, see Coleman and Webster, 1988). This does not exclude involvement of the amygdala and will be of interest to study in more detail in the future.

Our findings show that the modulatory effect of preceding fear conditioning, and therefore likely the amygdala, goes beyond the acquisition phase. Prior fear-conditioning and concomitant fear-extinction trials also impeded extinction of conditioned eyeblinks, which was accompanied by increased autonomic fear responses. Findings are in good agreement with the work by Farley et al. (2016), who showed that the modulatory effect of the amygdala is not restricted to acquisition, as predicted by the twostage theory of aversive conditioning, but is also present during retention of conditioned eyeblinks. Emotional preconditioning has been found to enhance the eyeblink responses to the CS and to the US (Neufeld and Mintz, 2001). Concomitant presentation of fear and eyeblink CSs during extinction training has likely the same effect. The most parsimonious explanation is increased salience, that is aversiveness, of the CS (and US) input to the cerebellum, likely gated by the amygdala (Weisz et al., 1992; Taub and Mintz, 2010; Farley et al., 2016, 2018). The hypothesis that the amygdala gates selective attention to the CS rather than emotional modulation of responding is further supported by our observation that ratings of valence and arousal toward the fear CS, and of unpleasantness of the fear US were not different between groups. Likewise, eyeblink conditioning is facilitated by a stressful event before conditioning, which also leads to increased activity of the amygdala (Servatius et al., 2001; Shors, 2004; Weiss et al., 2005; Duncko et al., 2007). In fact, it has been shown by Steinmetz et al. (2017) that the facilitatory effect of the amygdala in eyeblink conditioning does not require memory formation in the amygdala, which, as outlined in the Introduction, is at variance with the two-stage theory of aversive conditioning.

Findings of impeded extinction of conditioned eyeblinks were observed regardless of the temporal presentation protocols (i.e., overlapping, alternating, or successive presentation of fear and eyeblink CS extinction trials); that is, effects were not restricted to the time of the fear CS presentation. Extinction training on day 2 lasted for a maximum of $26 \mathrm{~min}$. Proposed effects of selective attention to the CS may be less only after more extended periods of extinction training (Itthipuripat et al., 2017).

One possible limitation of the present study is that eyeblink conditioning was acquired in a single session, and 
learning did not reach full saturation. Humans, however, acquire conditioned eyeblinks much faster than rodents (Spence, 1966). As stated above, the first conditioned eyeblink responses occur frequently within the first 10 paired CS/US trials (Kjell et al., 2018). Much of the learning is achieved at the end of a single session, and the additional increase in the incidence of $\mathrm{CR}$ across multiple sessions is comparatively small (Gerwig et al., 2010). Another possible limitation is that the interaction between conditioned fear and eyeblink responses was tested during extinction training, similar to studies testing additive response summation (Wolf, 1963; Weiss, 1964; Miller, 1969). Extinction of conditioned eyeblinks may have attenuated output of the cerebellar nuclei below threshold already after a limited number of trials. Magal and Mintz (2014) had mimicked eyeblink CRs by continuous stimulation of the cerebellar nuclei. The proposed third stage of learning, however, has never been tested directly during eyeblink conditioning in rodents.

Findings appear to contradict the observation that goaldirected eye movements may be beneficial in the treatment of posttraumatic stress disorder (see the "eye movement desensitization and reprocessing" (EMDR) method introduced by Shapiro, 1989). Eye movements involve the cerebellum, and it has been proposed that the cerebellum contributes to EDMR effects (Bergmann, 2000; Calancie et al., 2018). A recent fMRI study showed that EMDR in fact enhances the extinction of conditioned fear responses. This effect, however, was not specific to eye movements, but also occurred with an accompanying working memory task (de Voogd et al., 2018). The authors found that the activity of the amygdala was decreased, which was accompanied by altered connectivity with dorsolateral and ventromedial prefrontal pathways. Because of the known connections of the cerebellum with the dorsolateral and (shown more recently) ventromedial prefrontal areas, the cerebellum may well have a modulatory role in EDMR (Strick et al., 2009; Watson et al., 2009). The present data, however, show that a more direct inhibitory effect of the cerebellum on the amygdala may not be involved. Future studies, however, are needed to investigate other forms of cerebellar-dependent motor learning.

Experiments have been performed in men only. Results may be different in women particularly regarding learned fear responses (Lebron-Milad et al., 2012; Fenton et al., 2016). In rats, however, the role of the amygdala in eyeblink conditioning does not seem to be sex dependent (Bral et al., 2019). Furthermore, sex differences observed in eyeblink conditioning in rodents (Dalla and Shors, 2009) have not been replicated in humans (Wolf et al., 2009).

In conclusion, no evidence was found that cerebellumdependent conditioned eyeblink responses accelerate extinction of conditioned fear. Rather, recall of conditioned fear was facilitated. As expected, fear conditioning facilitated subsequent eyeblink conditioning, but also impeded its extinction, accompanied by increased fear responses. Findings agree with the sensory gating hypothesis of the amygdala but are difficult to explain with the two-stage (or three-stage) theory of aversive conditioning, which would predict the suppression of conditioned fear once conditioned eyeblinks are acquired.

\section{References}

Amano T, Unal CT, Paré D (2010) Synaptic correlates of fear extinction in the amygdala. Nat Neurosci 13:489-494.

Bengtsson F, Jirenhed DA, Svensson P, Hesslow G (2007) Extinction of conditioned blink responses by cerebello-olivary pathway stimulation. Neuroreport 18:1479-1482.

Bergmann U (2000) Further thoughts on the neurobiology of EMDR: the role of the cerebellum in accelerated information processing. Traumatology 6:175-200.

Boele HJ, Koekkoek SK, De Zeeuw Cl (2010) Cerebellar and extracerebellar involvement in mouse eyeblink conditioning: the ACDC model. Front Cell Neurosci 3:19.

Bracha V, Zbarska S, Parker K, Carrel A, Zenitsky G, Bloedel JR (2009) The cerebellum and eye-blink conditioning: learning versus network performance hypotheses. Neuroscience 162:787-796.

Bral SR, Farley SJ, Freeman JH (2019) Amygdala central nucleus inactivation impairs cerebellar dependent learning in female rats. Soc Neurosci Abstr 45:085.13.

Brunner E, Domhof S, Langer F (2002) Nonparametric analysis of longitudinal data in factorial experiments. New York: Wiley.

Burns RA, Kimmel HD (1975) Adaptational aspects of conditioning. In: Handbook of learning and cognitive processes, Vol 2, conditioning and behavior theory (Estes WK, ed), pp 99-142. Hillsdale, $\mathrm{NJ}$ : Erlbaum.

Butler CW, Wilson YM, Oyrer J, Karle TJ, Petrou S, Gunnersen JM, Murphy M, Reid CA (2018) Neurons specifically activated by fear learning in lateral amygdala display increased synaptic strength. eNeuro 5:ENEURO.0114-18.2018.

Calancie OG, Khalid-Khan S, Booij L, Munoz DP (2018) Eye movement desensitization and reprocessing as a treatment for PTSD: current neurobiological theories and a new hypothesis. Ann N Y Acad Sci 1426:127-145.

Cohen J (1988) Statistical power analysis for the behavioral sciences. Hillsdale, NJ: Erlbaum.

Coleman SR, Webster S (1988) The problem of volition and the conditioned reflex. Part II. Voluntary-responding subjects, 1951-1980. Behaviorism 16:17-49.

Craske MG, Mystkowski JL (2006) Exposure therapy and extinction: clinical studies. In: Fear and learning: from basic processes to clinical implications (Craske MG, Hermans D, Vansteenwegen D, eds), pp 217-233. Washington, DC: American Psychological Association.

Craske MG, Treanor M, Conway CC, Zbozinek T, Vervliet B (2014) Maximizing exposure therapy: an inhibitory learning approach. Behav Res Ther 58:10-23.

Cumming G (2012) Understanding the new statistics: effect sizes, confidence intervals, and meta-analysis. New York: Routledge Academic.

Dalla C, Shors TJ (2009) Sex differences in learning processes of classical and operant conditioning. Physiol Behav 97:229-238.

de Voogd LD, Kanen JW, Neville DA, Roelofs K, Fernández G, Hermans EJ (2018) Eye-movement intervention enhances extinction via amygdala deactivation. J Neurosci 38:8694-8706.

De Zeeuw Cl, Ten Brinke MM (2015) Motor learning and the cerebellum. Cold Spring Harb Perspect Biol 7:a021683.

Duncko R, Cornwell B, Cui L, Merikangas KR, Grillon C (2007) Acute exposure to stress improves performance in trace eyeblink conditioning and spatial learning tasks in healthy men. Learn Mem 14:329-335.

Ernst TM, Brol AE, Gratz M, Ritter C, Bingel U, Schlamann M, Maderwald S, Quick HH, Merz CJ, Timmann D (2019) The cerebellum is involved in processing of predictions and prediction errors in a fear conditioning paradigm. eLife 8:e46831.

Farley SJ, Freeman JH (2019) Optogenetic inhibition of amygdala central nucleus efferent pathways modulate cerebellum dependent learning. Soc Neurosci Abstr 45:085.15.

Farley SJ, Radley JJ, Freeman JH (2016) Amygdala modulation of cerebellar learning. J Neurosci 36:2190-2201. 
Farley SJ, Albazboz H, De Corte BJ, Radley JJ, Freeman JH (2018) Amygdala central nucleus modulation of cerebellar learning with a visual conditioned stimulus. Neurobiol Learn Mem 150:84-92.

Faul F, Erdfelder E, Buchner A, Lang A-G (2009) Statistical power analyses using $\mathrm{G} *$ Power 3.1: tests for correlation and regression analyses. Behav Res Methods 41:1149-1160.

Fenton GE, Halliday DM, Mason R, Bredy TW, Stevenson CW (2016) Sex differences in learned fear expression and extinction involve altered gamma oscillations in medial prefrontal cortex. Neurobiol Learn Mem 135:66-72.

Gerwig M, Hajjar K, Dimitrova A, Maschke M, Kolb FP, Frings M, Thilmann AF, Forsting M, Diener HC, Timmann D (2005) Timing of conditioned eyeblink responses is impaired in cerebellar patients. J Neurosci 25:3919-3931.

Gerwig M, Kolb FP, Timmann D (2007) The involvement of the human cerebellum in eyeblink conditioning. Cerebellum 6:38-57.

Gerwig M, Guberina H, Esser AC, Siebler M, Schoch B, Frings M, Kolb FP, Aurich V, Beck A, Forsting M, Timmann D (2010) Evaluation of multiple-session delay eyeblink conditioning comparing patients with focal cerebellar lesions and cerebellar degeneration. Behav Brain Res 212:143-151.

Gormezano I, Kehoe E (1975) Classical conditioning: some methodical-conceptual issues. In: Handbook of learning and cognitive processes (Estes WK, ed), pp 143-179. Hillsdale, NJ: Erlbaum.

Henry JD, Crawford JR (2005) The short-form version of the Depression Anxiety Stress Scales (DASS-21): construct validity and normative data in a large non-clinical sample. $\mathrm{Br} \mathrm{J}$ Clin Psychol 44:227-239.

Herry C, Ferraguti F, Singewald N, Letzkus JJ, Ehrlich I, Luthi A (2010) Neuronal circuits of fear extinction. Eur J Neurosci 31:599612.

Hesslow G, Ivarsson M (1996) Inhibition of the inferior olive during conditioned responses in the decerebrate ferret. Exp Brain Res 110:36-46.

Ho J, Tumkaya T, Aryal S, Choi H, Claridge-Chang A (2019) Moving beyond $P$ values: data analysis with estimation graphics. Nat Methods 16:565-566.

Hull CL (1943) Principles of behavior: an introduction to behavior theory. Oxford: Appleton-Century.

Itthipuripat S, Cha K, Byers A, Serences JT (2017) Two different mechanisms support selective attention at different phases of training. PLoS Biol 15:e2001724.

Jentsch VL, Wolf OT, Merz CJ (2020) Temporal dynamics of conditioned skin conductance and pupillary responses during fear acquisition and extinction. Int J Psychophysiol 147:93-99.

Kimble GA (1961) Hilgard and Marquis' "conditioning and learning". East Norwalk, CT: Appleton-Century-Crofts.

Kjell K, Lowgren K, Rasmussen A (2018) A longer interstimulus interval yields better learning in adults and young adolescents. Front Integr Neurosci 12:299.

Konorski J (1967) Integrative activity of the brain; an interdisciplinary approach. Chicago: University of Chicago.

Krabbe S, Gründemann J, Lüthi A (2018) Amygdala inhibitory circuits regulate associative fear conditioning. Biol Psychiatry 83:800-809.

Lebron-Milad K, Abbs B, Milad MR, Linnman C, RougemountBücking A, Zeidan MA, Holt DJ, Goldstein JM (2012) Sex differences in the neurobiology of fear conditioning and extinction: a preliminary fMRI study of shared sex differences with stress-arousal circuitry. Biol Mood Anxiety Disord 2:7-7.

LeDoux JE (2000) Emotion circuits in the brain. Annu Rev Neurosci 23:155-184

Lee T, Kim JJ (2004) Differential effects of cerebellar, amygdalar, and hippocampal lesions on classical eyeblink conditioning in rats. $J$ Neurosci 24:3242-3250.

Lennartz RC, Weinberger NM (1992) Analysis of response systems in Pavlovian conditioning reveals rapidly versus slowly acquired conditioned responses: support for two factors, implications for behavior and neurobiology. Psychobiology 20:93-119.
Lindquist DH, Mahoney LP, Steinmetz JE (2010) Conditioned fear in adult rats is facilitated by the prior acquisition of a classically conditioned motor response. Neurobiol Learn Mem 94:167-175.

Lonsdorf TB, Menz MM, Andreatta M, Fullana MA, Golkar A, Haaker J, Heitland I, Hermann A, Kuhn M, Kruse O, Meir Drexler S, Meulders A, Nees F, Pittig A, Richter J, Römer S, Shiban Y, Schmitz A, Straube B, et al. (2017) Don't fear "fear conditioning": methodological considerations for the design and analysis of studies on human fear acquisition, extinction, and return of fear. Neurosci Biobehav Rev 77:247-285.

Magal A, Mintz M (2014) Inhibition of the amygdala central nucleus by stimulation of cerebellar output in rats: a putative mechanism for extinction of the conditioned fear response. Eur $\mathrm{J}$ Neurosci 40:3548-3555.

McCormick DA, Thompson RF (1984) Cerebellum: essential involvement in the classically conditioned eyelid response. Science 223:296-299.

Medina JF, Nores WL, Mauk MD (2002) Inhibition of climbing fibres is a signal for the extinction of conditioned eyelid responses. Nature 416:330-333.

Merz CJ, Hermann A, Stark R, Wolf OT (2014) Cortisol modifies extinction learning of recently acquired fear in men. Soc Cogn Affect Neurosci 9:1426-1434.

Merz CJ, Kinner VL, Wolf OT (2018) Let's talk about sex ... differences in human fear conditioning. Curr Opin Behav Sci 23:7-12.

Mihailoff GA, Kosinski RJ, Azizi SA, Border BG (1989) Survey of noncortical afferent projections to the basilar pontine nuclei: a retrograde tracing study in the rat. J Comp Neurol 282:617-643.

Miller L (1969) Compounding of pre-aversive stimuli. J Exp Anal Behav 12:293-299.

Mintz M, Wang-Ninio Y (2001) Two-stage theory of conditioning: involvement of the cerebellum and the amygdala. Brain Res 897:150-156.

Neufeld M, Mintz M (2001) Involvement of the amygdala in classical conditioning of eyeblink response in the rat. Brain Res 889:112117.

Norton PJ (2007) Depression Anxiety and Stress Scales (DASS-21): psychometric analysis across four racial groups. Anxiety Stress Coping 20:253-265.

Ohman A (1972) Factor analytically derived components of orienting, defensive, and conditioned behavior in electrodermal conditioning. Psychophysiology 9:199-209.

Ohman A (1974) Orienting reactions, expectancy learning, and conditioned responses in electrodermal conditioning with different interstimulus intervals. Biol Psychol 1:189-200.

Oldfield RC (1971) The assessment and analysis of handedness: the Edinburgh inventory. Neuropsychologia 9:97-113.

Pérez OD, Martín RS, Soto FA (2018) Exploring the role of stimulus similarity on the summation effect in causal learning. Exp Psychol 65:183-200.

Phelps EA, LeDoux JE (2005) Contributions of the amygdala to emotion processing: from animal models to human behavior. Neuron 48:175-187.

Pineles SL, Orr MR, Orr SP (2009) An alternative scoring method for skin conductance responding in a differential fear conditioning paradigm with a long-duration conditioned stimulus. Psychophysiology 46:984-995.

Prokasy WF, Ebel HC (1967) Three components of the classically conditioned GSR in human subjects. J Exp Psychol 73:247-256.

Rescorla RA, Solomon RL (1967) Two-process learning theory: relationships between Pavlovian conditioning and instrumental learning. Psychol Rev 74:151-182.

Rogan MT, Stäubli UV, LeDoux JE (1997) Fear conditioning induces associative long-term potentiation in the amygdala. Nature 390:604-607.

Rosenkranz JA, Moore H, Grace AA (2003) The prefrontal cortex regulates lateral amygdala neuronal plasticity and responses to previously conditioned stimuli. J Neurosci 23:11054-11064. 
Schroeder BW, Shinnick-Gallagher P (2005) Fear learning induces persistent facilitation of amygdala synaptic transmission. Eur $\mathrm{J}$ Neurosci 22:1775-1783.

Servatius RJ, Brennan FX, Beck KD, Beldowicz D, Coyle-DiNorcia K (2001) Stress facilitates acquisition of the classically conditioned eyeblink response at both long and short interstimulus intervals. Learn Motiv 32:178-192.

Shah DA, Madden LV (2004) Nonparametric analysis of ordinal data in designed factorial experiments. Phytopathology 94:33-43.

Shapiro F (1989) Efficacy of the Eye Movement Desensitization procedure in the treatment of traumatic memories. J Trauma Stress 2:199-223.

Shors TJ (2004) Learning during stressful times. Learn Mem 11:137144.

Spence KW (1966) Cognitive and drive factors in the extinction of the conditioned eye blink in human subjects. Psychol Rev 73:445458.

Steinmetz AB, Ng KH, Freeman JH (2017) Memory consolidation within the central amygdala is not necessary for modulation of cerebellar learning. Learn Mem 24:225-230.

Strick PL, Dum RP, Fiez JA (2009) Cerebellum and nonmotor function. Annu Rev Neurosci 32:413-434.

Taub AH, Mintz M (2010) Amygdala conditioning modulates sensory input to the cerebellum. Neurobiol Learn Mem 94:521-529.

Thompson RF, Donegan NH, Clark GA, Lavond DG, Lincoln JS, Madden J, Iv Mamounas LA, Mauk MD, McCormick DA (1987) Neuronal substrates of discrete, defensive conditioned reflexes, conditioned fear states, and their interactions in the rabbit. In:
Classical conditioning, Ed 3 (Prokasy WF, Thompson RF, Gormezano I, eds), pp 371-399. Hillsdale, NJ: Erlbaum.

Utz A, Thürling M, Ernst TM, Hermann A, Stark R, Wolf OT, Timmann D, Merz CJ (2015) Cerebellar vermis contributes to the extinction of conditioned fear. Neurosci Lett 604:173-177.

Watson TC, Jones MW, Apps R (2009) Electrophysiological mapping of novel prefrontal-cerebellar pathways. Front Integr Neurosci 3:18.

Weiss C, Sametsky E, Sasse A, Spiess J, Disterhoft JF (2005) Acute stress facilitates trace eyeblink conditioning in C57BL/6 male mice and increases the excitability of their CA1 pyramidal neurons. Learn Mem 12:138-143.

Weiss SJ (1964) Summation of response strengths instrumentally conditioned to stimuli in different sensory modalities. J Exp Psychol 68:151-155.

Weiss SJ (1972) Stimulus compounding in free-operant and classical conditioning. A review and analysis. Psychol Bull 78:189-208.

Weisz DJ, Harden DG, Xiang Z (1992) Effects of amygdala lesions on reflex facilitation and conditioned response acquisition during nictitating membrane response conditioning in rabbit. Behav Neurosci 106:262-273.

Wolf MM (1963) Some effects of combined S-DS. J Exp Anal Behav 6:343-347.

Wolf OT, Minnebusch D, Daum I (2009) Stress impairs acquisition of delay eyeblink conditioning in men and women. Neurobiol Learn Mem 91:431-436.

Zuchowski ML, Timmann D, Gerwig M (2014) Acquisition of conditioned eyeblink responses is modulated by cerebellar tDCS. Brain Stimul 7:525-531. 